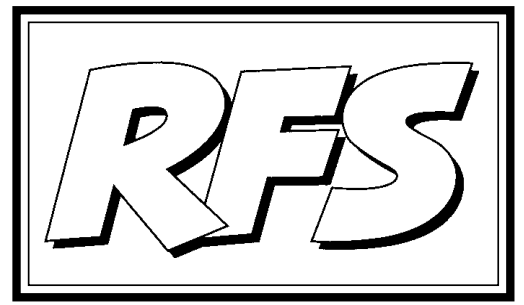

Revista de Fomento Social, 54 (1999), 537-540

\title{
Deuda externa
}

En el mes de mayo pasado se reunieron los Superiores Provinciales de la Compañía de Jesús de toda Europa. Fruto de su trabajo en esos días elaboraron una carta dirigida a los ministros de economía del Grupo de los países más industrializados (G7) que se iban a reunir en Colonia.

\section{A los Señores Ministros de economía del Grupo G7}

Como Superiores Provinciales de la Compañía de Jesús, queremos agregar nuestras voces a las expresiones de preocupación respecto al problema de la deuda que aflige a tantos países pobres. La mayoría de estos países se encuentran en África Subsahariana, pero otras regiones del mundo, del mundo, notablemente América Latina y el Caribe, se encuentran igualmente afectadas. Nuestros colegas jesuitas en los países del Tercer Mundo dan testimonio del impacto devastador de la crisis de la deuda, sobre todo en los sectores más empobrecidos. 


\section{La montaña de la Deuda}

En muchos países en vías de desarrollo, la deuda externa es inmensa. Por ejemplo, la deuda de los países del África Subsahariana alcanza los 220 mil millones de dólares. Esto representa $\$ 365$ por persona, mientras que el PNB por persona es tan solo \$ 308. En muchos países africanos, se gasta más en el servicio de la deuda que en salud y demás servicios sociales. La falta de fondos suficientes para los servicios sanitarios y el control de las epidemias se traduce en numerosas muertes, así como la incapacitación permanente de muchas personas como consecuencia una elevada tasa de analfabetismo. El dinero que debería gastarse en infraestructura básica, salud, protección del medio ambiente y desarrollo local se exporta a los países ricos. A veces, los programas de reestructuración, impuestos porinstituciones financieras con sede en el Norte, han llevado a la desestabilización social y política.

El peso de la deuda perjudica gravemente el desarrollo de los países del Tercer Mundo. En África, casi la mitad de cada dólar que se gana en concepto de exportaciones, se gasta en la financiación de la deuda.

Aproximadamente la tercera parte de esta suma vuelve a los países acreedores. No debe sorprendernos que los gobiernos africanos se pregunten hasta qué punto les ayuda el aumento de sus exportaciones. Además, de cada dólar recibido en forma de ayuda, el $20 \%$ pasa a los acreedores privados. Esta situación frena la reforma de las finanzas públicas, pues los beneficios se pierden en la financiación de la deuda, en lugar de invertirse en los servicios básicos.

\section{Aspectos éticos}

En la situación de necesidad extrema que existe ahora en África Subsahariana, América Latina, el Caribe y otras regiones, no podemos seguir insistiendo en la obligación ética de pagar la totalidad de la deuda internacional.

Aunque resulte difícil identificar con precisión a los responsables de la crisis de la deuda, sí podemos afirmar que las personas humildes no lo son, y ellas son las más afectadas. Entre los factores más importantes, se puede señalar el persistente déficit presupuestario de los Estados Unidos, que sostuvo una tasa de interés elevada en la década de los ochenta. Al mismo tiempo, hubo un colapso en el precio de las materias primas, y un aumento en el precio del petróleo. Todo esto llevó 
a la desvalorización de las monedas locales, agravando más todavía el problema de la financiación de la deuda, que se calculaba en dólares.

En algunos países, el dinero prestado fue malgastado en proyectos grandiosos, favoreciendo a élites corruptas. Con frecuencia, estas mismas élites se mantenían en el poder debido a sus vínculos con una u otra de las superpotencias. A partir del colapso del bloque comunista, estos países han perdido la importancia estratégica, y han quedado abandonados a su suerte. A pesar de que los sectores más pobres de estos países no se vieron beneficiados con el dinero prestado, ahora sienten todo el peso de la deuda acumulada.

No habría que olvidar la obligación moral de los países del Norte de ayudar a los del Sur, debido al pasado colonial. No ha habido recompensa alguna por el gran saqueo de recursos materiales y humanos del que fueron objeto éstos. Además, las fronteras políticas impuestas por las potencias coloniales, sin tener en cuenta el factor étnico, han sido una causa importante de inestabilidad interna e internacional. La explotación comercial del Sur por parte del norte es un gran crimen, no solamente histórico, sino actual. Los países del Norte aprovecharon el Sur como fuente de materias primas baratas pero, debido a los elevados aranceles de los productos manufacturados, resulta muy difícil que los países del Tercer Mundo desarrollen su propia industria. Muchas entidades comerciales radicadas en el Primer Mundo logran controlar los precios del mercado mundial, perjudicando a los productores y agricultores del Tercer Mundo. En realidad, son los países del Norte los que tienen una gran deuda con los del Sur, y no a la inversa.

Nadie está obligado a ser condenado a la miseria para devolver el dinero a acreedores ricos, y menos todavía cuando la deuda ha sido contratada en circunstancias tan cuestionables. Al contrario, en una situación de tan extrema necesidad, la obligación moral de ayudar al prójimo exige que los países del Norte apoyen a sus vecinos del Sur. La anulación de la deuda impagable del Tercer Mundo puede significar algunos inconvenientes para los países del Norte, pero estos tampoco serán tan grandes.

\section{Conclusión}

Comojesuitas, entendemos nuestra misión en términos del servicio de lafe, pero la promoción de la justicia, forma una parte ineludible de esta misión. No podemos sentirnos en paz con Dios mientras seguimos divididos entre nosotros mismos por 
la desigualdad, la pobreza y las relaciones injustas. Por lotanto, queremos apoyar sin reservas la «Campaña Deuda externa», y otras similares, que piden la anulación inmediata de la deuda impagable del Tercer Mundo. Pedimos que los países del Norte no se contenten con tal medida mínima, sino que se animen a lanzar una campaña concertada de apoyo a los países del Tercer Mundo en su búsqueda de un desarrollo sostenible. Además, pedimos a los países del Norte que se encarguen de ordenar su propia casa, buscando nuevos modelos de desarrollo que no dependan de políticas proteccionistas ni de la explotación de materias primas baratas provenientes del Tercer Mundo. 